\title{
Data Transmission at 16.8kb/s Over 32kb/s ADPCM Channel
}

\author{
Muhanned AL-Rawi, Muaayed AL-Rawi
}

\begin{abstract}
This paper presents three models of Quadrature Amplitude Modulation (QAM) modem operating at data rate of $16.8 \mathrm{~kb} / \mathrm{s}$ to be transmitted over $32 \mathrm{~kb} / \mathrm{s}$ Adaptive Differential Pulse Code Modulation (ADPCM) channel. These modems operate at symbol rates of 2400, 2800, and 3360 baud with associated number of bits per symbol of 7, 6, and 5 respectively. The performance of ADPCM is studied considering these modems with different constellations. The simulation results show that the performance of ADPCM degrades as the symbol rate decreases or number of bits per symbol increases. Also, the performance with circular constellation is better than rectangular one.
\end{abstract}

Index Terms: - QAM modem, 32kb/s ADPCM.

\section{IMPORTANCE OF STUDY}

With the increase in demand for efficient use of digital communication channel, various types of highly effective speech coding methods have been developed [2],[5], [8],[11],[24],[27],[28]. As one of these coding methods is international standard 32kb/s Adaptive Differential Pulse Code Modulation (ADPCM)[2]. The superior performance, economy and application flexibility of ADPCM relative to other bandwidth reduction techniques were the prime reasons for its selection.

The specification of ADPCM opens the door to a host of applications in telecommunication networks [12],[13],[14],[15],[22],[23],[25].These applications can be divided into three categories: telephone company use, end customer applications, and new service offerings.

\section{STATEMENT OF PROBLEM}

A recommended definition of ADPCM algorithm was published by International Telephone Telegraph Consultative Committee [CCITT, the new name is International Telecommunication Union (ITU)] as Recommendation G.721 [2].

It was recognized at study group XVIII meeting [2] that voiceband data performance at $9.6 \mathrm{~kb} / \mathrm{s}$ would not be acceptable with standard $32 \mathrm{~kb} / \mathrm{s}$ ADPCM because ADPCM adds severe nonlinear distortion to the voiceband data signal with speed greater than $4.8 \mathrm{~kb} / \mathrm{s}$.

Thus, the interest of many research workers has been directed towards the ADPCM codec capable of providing better performance for speech and voiceband data signal at speed greater than $4.8 \mathrm{~kb} / \mathrm{s}$.

\section{METHODOLOGY OF SOLUTION}

Exhaustive work had been done to accommodate high speed voiceband data signal either by modifying the algorithm of ADPCM [3],[4],[6], [7], [9], [10], [17], [18], [21], [29] or by modifying the model of data transmission[16],[18],[19],[20]. One way to modify the model of data transmission is to use different constellations of Quadrature Amplitude Modulation (QAM) signal. This idea was firstly studied by AL-Rawi in [16],[18] to improve the performance of ADPCM.

\section{OBJECTIVE}

The main objective of this paper is to modify the model of data transmission at data rate of $16.8 \mathrm{~kb} / \mathrm{s}$ in order to reduce the distortion of ADPCM

\section{STRUCTURE OF ADPCM}

The algorithm of $32 \mathrm{~kb} / \mathrm{s}$ ADPCM which is described here is as in CCITT G.726 [3]. Fig.1 shows simplified block diagram of ADPCM codec. Two major components form the algorithm: an adaptive quantizer and an adaptive predictor. The relation between the encoder and the decoder is also depicted. The difference between them is that the encoder has adaptive quantizer $(\mathbf{Q})$ and inverse adaptive quantizer $\left(\mathbf{Q}^{\mathbf{- 1}}\right)$, while, the decoder has inverse adaptive quantizer only. The decoder is simply a subset of the encoder and transmits r(n) as its output instead of $\mathrm{c}(\mathrm{n})$. The adaptive predictor, which is composed of two poles and six zeros, computes an input 
signal estimate $\hat{\mathrm{s}}(\mathrm{n})$ which is subtracted from input signal $\mathrm{s}(\mathrm{n})$ resulting in a difference signal $\mathrm{d}(\mathrm{n})$. The adaptive quantizer codes $d(n)$ into 4-bit codeword $c(n)$ which is sent over the transmission facility. At the receiving end, an ADPCM decoder uses $\mathrm{c}(\mathrm{n})$ to attempt to reconstruct the original signal s(n). Actually, only $r(n)$ can be reconstructed which is related to the original input signal s(n) by

$$
r(n)=s(n)+e(n)
$$

where

$$
\mathrm{e}(\mathrm{n})=\mathrm{dq}(\mathrm{n})-\mathrm{d}(\mathrm{n})=\mathrm{r}(\mathrm{n})-\mathrm{s}(\mathrm{n})
$$

is the error introduced by the quantizer, and $\mathrm{dq}(\mathrm{n})$ is the output of inverse adaptive quantizer .

A typical measure of the ADPCM performance is given by signal-to-noise ratio (SNR)

$$
\mathrm{SNR}=\mathrm{E}\left[\mathrm{s}^{2}(\mathrm{n})\right] / \mathrm{E}\left[\mathrm{e}^{2}(\mathrm{n})\right]=\sigma_{\mathrm{s}}{ }^{2} / \sigma_{\mathrm{e}}{ }^{2}
$$

Where $\mathrm{E}$ denotes expectation, $\sigma_{\mathrm{s}}{ }_{\mathrm{s}}^{2}$ is the power (or variance) of input signal, $\& \sigma_{\mathrm{e}}{ }^{2}$ is the power (or variance) of the error signal.

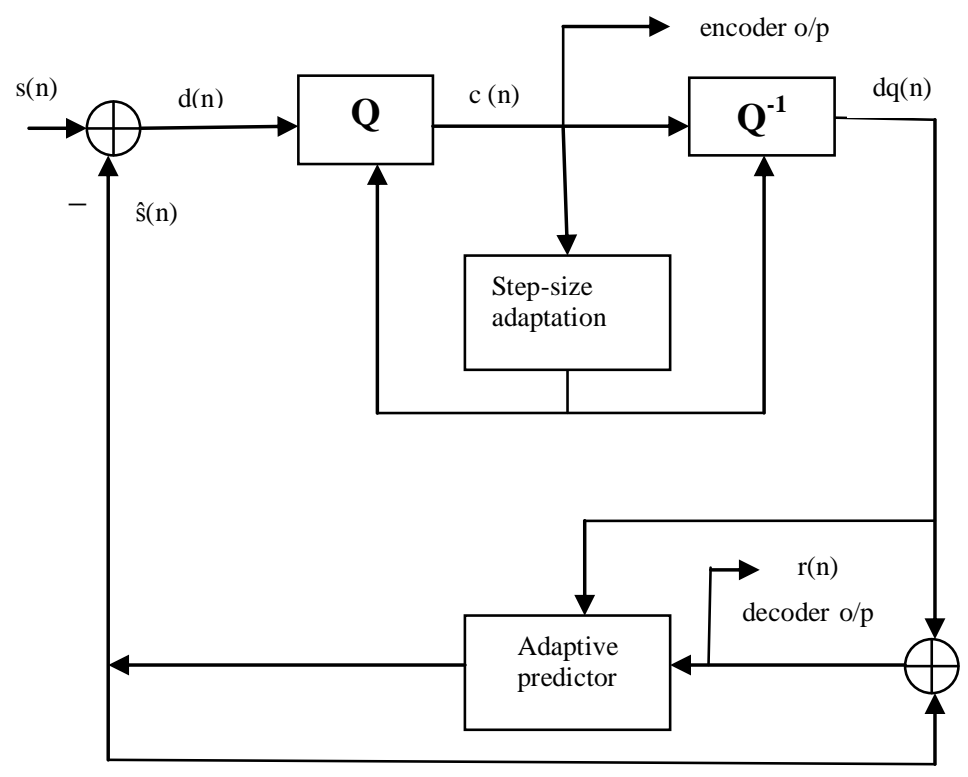

Fig.1 ADPCM Codec

\section{QAM MODEM}

The first QAM modem named modem-I operates at symbol rate of 2400 baud with each symbol is represented by 7 bits ( trellis coding is excluded) giving data rate of $2400 \times 7=16.8 \mathrm{~kb} / \mathrm{s}$. The number of points in M-ary QAM constellation is equal to $2^{7}=128$ points, while, modem V.34[1] uses the same symbol rate but with 192-point or 224-point constellation. The design of QAM constellation plays important role in reducing the effect of channel noise [26], also, in reducing the distortion of ADPCM[16]. Some of constellations which are considered here are shown in Fig.2, for 128-point, rectangular, \& $(6,12,19,27)$ circular. Because of symmetry, parts of rectangular and circular constellations are drawn.

The second QAM modem named modem-II operates at symbol rate of 2800 baud with each symbol is represented by six bits (trellis coding is excluded) giving data rate of $2800 \times 6=16.8 \mathrm{~kb} / \mathrm{s}$, with $2^{6}=64$-point constellation, while, modem V.34 uses the same symbol rate but with 96-point or 112-point constellation. Fig.3 shows some of 64-point constellations, rectangular,\& $(6,12,19,27)$ circular.

The third QAM modem named modem-III operates at symbol rate of 3360 baud ( the maximum allowable symbol rate is 3429 baud[1]) with each symbol is represented by five bits (trellis coding is excluded) giving data rate of $3360 \times 5=16.8 \mathrm{~kb} / \mathrm{s}$, with $2^{5}=32$-point constellation. Fig. 4 shows some of 32-point constellations, rectangular, $(4,11,17), \&(5,11,16)$ circular. 


\section{COMPUTER SIMULATION TEST}

A series of computer simulation tests have been carried out on ADPCM codec using the three QAM modem signals at $16.8 \mathrm{~kb} / \mathrm{s}$ with constellations shown in Figs.2-4. The performance of ADPCM is measured by calculating SNR in equation 3.

Table 1 shows the results of testing ADPCM using modem-I. It seems that the performance of ADPCM with circular constellation is better than rectangular one by approximately $0.3 \mathrm{~dB}$.

Table 2 shows the results of testing ADPCM using modem-II. It seems that the performance of ADPCM with circular constellation is better than rectangular one by approximately $0.4 \mathrm{~dB}$.

Table 3 shows the results of testing ADPCM using modem-III. It seems that the performance of ADPCM with circular constellation is better than rectangular one by approximately $0.5 \mathrm{~dB}$.

The comparison among the three modems shows that the performance of ADPCM with modem-III is better than its performance with modem-II by approximately $1.1 \mathrm{~dB}$ and the later is better than modem-I by approximately $1.2 \mathrm{~dB}$.

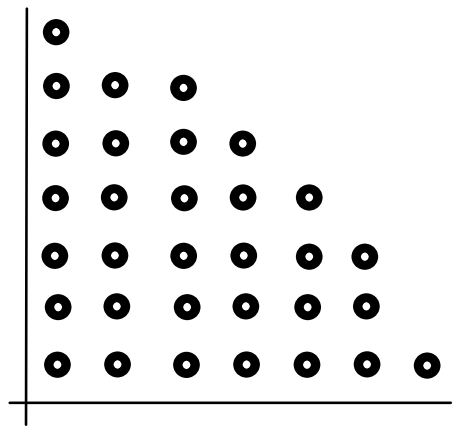

(a) Rectangular

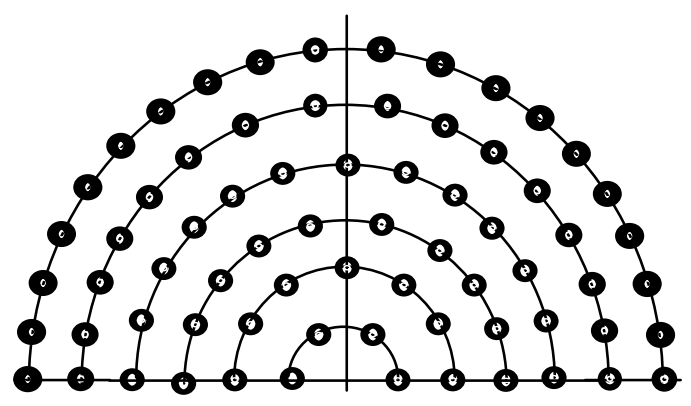

(b) $\quad(6,12,18,24,30,38)$

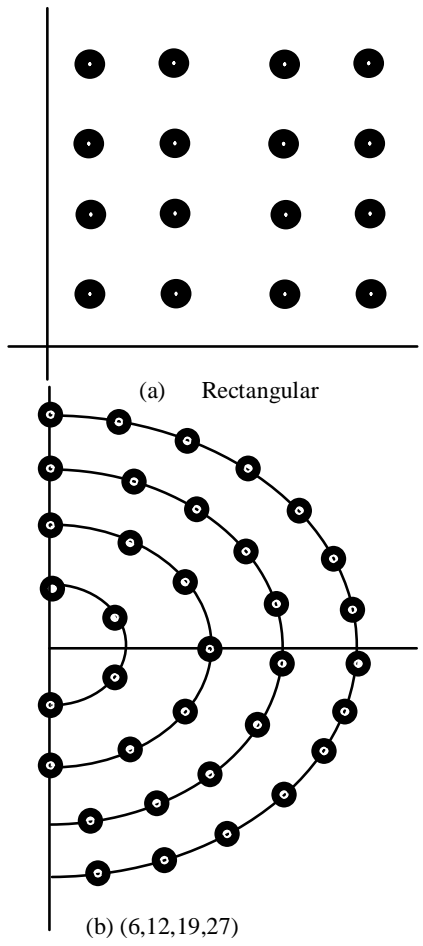

Fig.3 64-ary QAM constellations

Fig.2 128-ary QAM constellations

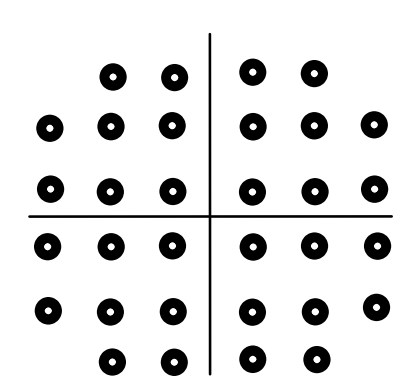

(a) Rectangular
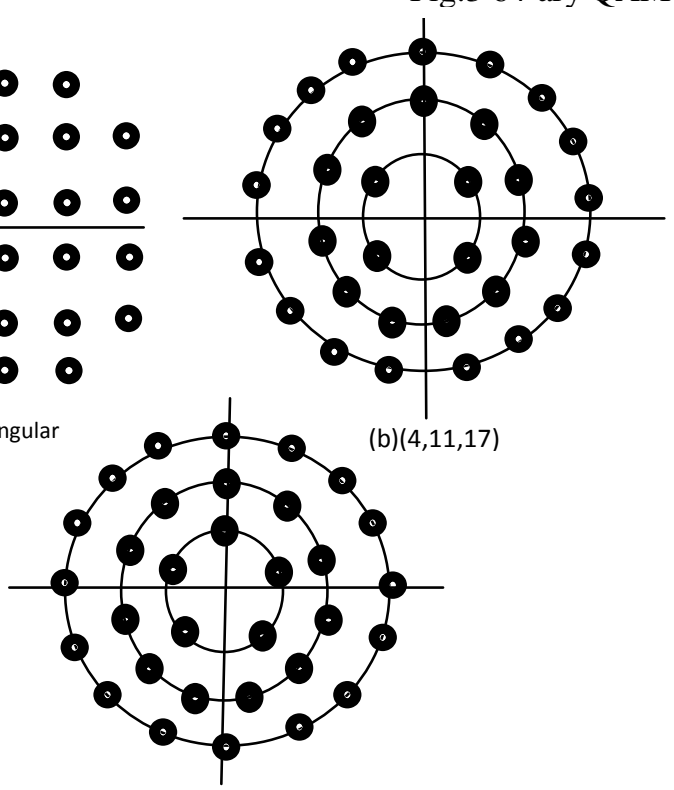

(c) $(5,11,16)$

Fig.4 32-ary QAM constellations 
Table 1 Performance of ADPCM

\begin{tabular}{|l|l|l|}
\hline & \multicolumn{2}{|l|}{ Modem-I } \\
\hline \multirow{3}{*}{ SNR(dB) } & Rect & $(6,12,19,27)$ \\
\cline { 2 - 3 } & 19.7 & 20 \\
& & \\
\hline
\end{tabular}

Table 2 Performance of ADPCM

\begin{tabular}{|l|l|l|}
\hline & \multicolumn{2}{|l|}{ Modem-II } \\
\hline \multirow{3}{*}{ SNR(dB) } & Rect & $(6,12,19,27)$ \\
\cline { 2 - 3 } & 20.9 & 21.3 \\
& & \\
\hline
\end{tabular}

Table 3 Performance of ADPCM

\begin{tabular}{|l|l|l|l|}
\hline & \multicolumn{3}{|l|}{ Modem-III } \\
\hline \multirow{3}{*}{ SNR(dB) } & Rect & $(4,11,17)$ & $(5,11,16)$ \\
\cline { 3 - 4 } & 21.8 & 22.2 & 22.3 \\
& & & \\
\hline
\end{tabular}

\section{SUMMARY AND CONCLUSION}

Three QAM modems operate at data rate of $16.8 \mathrm{~kb} / \mathrm{s}$ have been considered in order to reduce the nonlinear distortion of ADPCM. The simulation results show that the performance of ADPCM with modem-III is better than modem-II and the later is better than modem-I. Also, the performance with circular constellation is better than rectangular one.

\section{REFRENCES}

[1] A modem operating at data signaling rates of up to 33600bit/s for use on the general switched telephone network and on leased point-to point 2-wire telephone-type circuits, CCITT Recommendation V.34-1998.

[2] $32 \mathrm{~kb} / \mathrm{s}$ ADPCM, CCITT Recommendation G.721-1984.

[3] 40, 32,24,16 kb/s ADPCM, CCITT Recommendation G.726-1990.

[4] 5-,4-,3-,2- bit/sample embedded ADPCM, CCITT Recommendation G.727-1990

[5] E. Jahangiri, and S. Ghaemmghami, "Very low rate scalable speech coding through classified embedded matrix quantization", EURASIP Journal on Advances in Signal Processing, Vol.2010, 2010.

[6] H. Mustafa, et al., "Overview and performance of CCITT/ANSI embedded ADPCM algorithm", IEEE Transaction on Communication, Vol.41, PP.391-399, 1993.

[7] Comparison of ADPCM algorithms, ITU-T Recommendation G.726 Appendix III-1994.

[8] Coding of speech at $8 \mathrm{~kb} / \mathrm{s}$ using conjugate structure algebraic code excited linear prediction(CSACELP), ITU-T Recommendation G.729-1996.

[9] Digital circuit multiplication equipment using G.726 ADPCM \& digital speech interpolation, ITU-T Recommendation G.763-1998.

[10] ADPCM DCME configuration map report, ITU-T Recommendation G.776.3-2000.

[11] J. Patel, et al., " A comparison of LBG \& ADPCM speech compression techniques", in Proc. of IEEE International Joint Conference on Computer, Information, Systems Sciences, and Engineering, 2008.

[12] K. Sanjeev, "Stabilization and glitch minimization for CCITT Recommendation G.726 speech codec during packet loss scenarios by regressor control and internal state updates of the decoding process", U.S. Patent 20090125302, May 14, 2009.

[13] K. Satish, M. Mundra, and C. Daniel, "Interoperability of ADPCM encoded voice communications", U.S. Patent 20060171372, August 3, 2006.

[14] L. Chu, "Adaptive differential pulse code modulation/demodulation system and method", U.S. Patent 201001183092, July 22, 2010.

[15] L. Yen-Shih, "ADPCM encoding and decoding method and system with improved step size adaptation thereof ", U.S. Patent 20080109219, May 8, 2008.

[16] M. AL-Rawi, et al., "Computer simulation for newly designed 9.6kb/s data transmission system over standard ADPCM", in Proc. of Ninth International Conference on Microelectronics, Bandung, Indonesia, 1997.

[17] M. AL-Rawi, et al., "Simulation results of newly designed ADPCM for data transmission at 9.6kb/s", in Proc. of Ninth International Conference on Microelectronics, Bandung, Indonesia, 1997.

[18] M. AL-Rawi, "Newly designed 9.6kb/s data transmission system over various algorithms of ADPCM", Ph.D. Dissertation, Dept. Elect. Eng., Bandung Institute of Technology, Indonesia, 1998

[19] M. AL-Rawi, and M. AL-Rawi, "Modified QAM modem for data transmission at 9.6kb/s over ADPCM link", International Proceeding of Computer Science and Information Technology [Online] , Vol.19, 2011. Available: http://www.ipcsit.com/ 
[20] M. AL-Rawi, and M. AL-Rawi, "Performance of asynchronous tandem standard 32kb/s ADPCM systems using QAM signal", Proceedings of SPIE, Vol.8350, 2012. http://dx.doi.org/10.1117/12.920582.

[21] N. Bevenuto, \& W.R. Daumer, "Two approaches for waveform coding of $9.6 \mathrm{~kb} / \mathrm{s}$ voiceband data signals through $32 \mathrm{~kb} / \mathrm{s}$ ADPCM", IEEE Transaction on Communication, Vol.3, PP.382-385, 1988.

[22] R. Mark , C. Yaakov and F. Eli , "Method and apparatus for smooth convergence during audio discontinuous transmission", U.S. Patent 20100260273, October 14, 2010.

[23] R. Mark, and F. Eli, "Adaptive error protection for wireless communications", U.S. Patent 20100138724, June 3, 2010.

[24] S. Dusan, et al., "Speech compression by polynomial approximation", IEEE Transaction on Audio, Speech, \& Language Processing, Vol.15, No.2, PP.387-395, 2007.

[25] T. Lijun, "Rom addressing method for an ADPCM decoder implementation", U.S. Patent 20070153919, July 5, 2007.

[26] T. Melvil, et al, "Digital amplitude-phase keying with M-ary alphabets", IEEE Transaction on Communication, Vol.22, No.2, PP.168-180, 1974.

[27] W. Chu, Speech coding algorithms: foundation and evolution of standardized coders, John Wiley \& Sons, New York, USA, 2003.

[28] W. Chu, " A scalable MELP coder based on embedded quantization of the line spectral frequencies", in Proc. of International Symposium on Intelligent Signal Processing \& Communication Systems, Hong Kong, 2005.

[29] Z. Shampiro, "Adaptive differential pulse code modulation system", U.S. Patent 4860313, 1989.

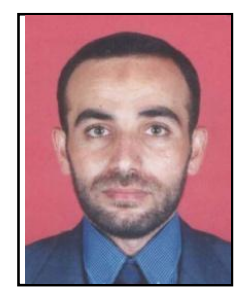

Muhanned AL-Rawi was born in Iraq,1969. He received B.Sc. degree in electrical engineering from AL-Mustansiryia University, Iraq, in 1990, M.Sc. degree in communication and electronics engineering from Baghdad University, Iraq, in 1993, and Ph.D. degree in telecommunication engineering from Bandung Institute of Technology, Indonesia, in 1999. He is currently with the department of electrical engineering, University of Ibb, Yemen. His research interests include digital communications, and digital signal processing.

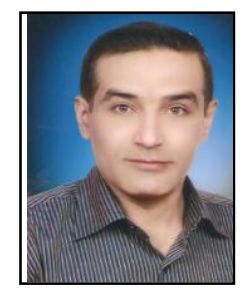

Muaayed AL-Rawi was born in Iraq, 1971. He received B.Sc. degree in electrical and nuclear engineering from Baghdad University, Iraq, in 1992, and M.Sc. degree in communication and electronics engineering from Jordan University of Science and Technology, Jordan, in 1999. He had worked as nuclear and electrical engineer for several years at Iraqi Atomic Energy Organization, Iraq. Currently he is with department of electrical engineering, AL-Mustansiryia University, Iraq. His research interests include biomedical engineering, digital communications, and digital signal processing. 